\title{
Superlotação no sistema socioeducativo: uma análise sociológica sobre normativas e disputas no Brasil e na Franç̣
}

\section{Juliana Vinuto* (1) \\ Géraldine Bugnon** (I)}

\section{Resumo}

Este artigo analisa a superlotação no sistema socioeducativo enquanto um objeto sociológico, com base em discussão sobre legislações e diretrizes, nacionais e interestatais, que tratam sobre a superlotação em centros de internação para adolescentes a quem se atribui a prática de ato infracional. Para tanto, realiza-se uma análise comparada entre dois países com atuações diferenciadas no tratamento da questão, Brasil e França. A partir da descrição do sistema de sanções a adolescentes acusados de atos infracionais nos dois países, propomos um debate que complexifica o próprio conceito de superlotação para, em seguida, apresentar como este é debatido nos contextos brasileiro e francês, evidenciando singularidades e disputas sobre modos de lidar com a superlotação em instituições privativas de liberdade para adolescentes. Tal análise permite definir a superlotação como resultado político da interação entre sistema de justiça, governos e ativistas, o que abre espaço para questionar a privação de liberdade como resposta inevitável e autoevidente para lidar com atos infracionais.

Palavras-chave: superlotação, punição, adolescentes, encarceramento, medida socioeducativa de internação.

\footnotetext{
* Universidade Federal Fluminense, Niterói, RJ, Brasil.

** Haute École de Travail Social, Genebra, Suiça.
} 


\section{Overcrowding in juvenile detention systems: a sociological analysis on norms and disputes in Brazil and France}

\section{Abstract}

This article analyzes overcrowding in the juvenile detention system as a sociological object, based on a discussion of national and interstate legislation and guidelines that address overcrowding in detention centers for adolescents who are accused of committing infractions. To this end, a comparative analysis is made between two countries with differentiated actions in dealing with the issue, Brazil and France. Based on the description of the system of sanctions for adolescents accused of infractions in the two countries, we propose a debate that complexifies the concept of overcrowding itself, and then present how it is discussed in the Brazilian and French contexts, which highlights singularities and disputes over ways of dealing with overcrowding in juvenile detention facilities. This analysis allows us to define overcrowding as a political outcome of the interaction between the justice system, governments, and activists, which opens space for questioning deprivation of liberty as an inevitable and self-evident response to dealing with juvenile offenses.

Keywords: overcrowding, punishment, adolescents, incarceration, juvenile detention center.

\section{Considerações iniciais}

superlotação em instituições de privação de liberdade brasileiras,
como prisões, unidades de medida socioeducativa, hospitais de
custódia e tratamento psiquiátrico, dentre outras, costuma ser definida como um problema crônico, operando como uma espécie de sinônimo para tais instituições (Beato Filho et al., 2020). Apesar de sua centralidade para a rotina dessas instituições, o conceito de superlotação ainda é insuficientemente debatido. Por isso, a superlotação é constantemente constatada como se seu significado fosse autoevidente. Este texto almeja contribuir com esse debate ao trazer luz para as disputas de sentido sobre o que seria, de fato, superlotação. 
Uma definição corriqueiramente utilizada é a de que a superlotação ocorre quando há mais pessoas encarceradas do que lugares oficialmente disponíveis na instituição, isto é, quando há mais internos do que suporta a unidade. Entretanto, como defendem Ariza Higuera e Torres Gomez (2019), este não deve ser assumido com o único critério para avaliar a relação entre espaço, pessoas e privação de liberdade, sendo necessário pensar a superlotação em uma perspectiva mais ampla de garantia de direitos. Para além das limitações de estrutura física e espaço, a superlotação também deve ser considerada a partir da existência de objetos de primeira necessidade em quantidade suficiente - desde pratos até material de limpeza -, número adequado de profissionais, de espaços sanitários, educativos, de esporte, cultura, lazer, atendimento jurídico e visita familiar, dentre outros pontos relevantes.

A superlotação também é considerada um impedimento central para a realização de um atendimento legalmente adequado, pois, com um número de internos acima da capacidade, há mais atividades a ser realizadas, menos tempo disponível para o planejamento e execução de projetos, mais conflitos a administrar, maior dificuldade na manutenção da higiene local etc. A superlotação também impede a concretização de um ambiente seguro para os internos, já que a imposição do medo passa a ser vista como ferramenta preventiva de trabalho (Vinuto, 2020). Nesse contexto, os direitos dos internos passam a ser organizados em uma escala informal de prioridades em que qualquer proposta que vá além do mínimo é considerada como além das capacidades institucionais (D’Angelo; Hernández, 2017). Como vemos, a superlotação afeta grande parte das decisões cotidianas em um contexto de privação de liberdade e costuma ser vista como uma coerção superior que se impõe frente aos interesses individuais. Por isso, há um certo consenso de que, enquanto não for solucionada, nenhum outro problema pode ser superado. Desse modo, a superlotação é apresentada como um problema institucional, ao mesmo tempo em que oferece uma justificativa para os problemas existentes na instituição (Vinuto, 2020). 
O objetivo deste artigo é propor uma discussão sobre algumas respostas legais à superlotação em unidades socioeducativas em dois países distintos, Brasil e França. ${ }^{1}$ Enquanto nos dois países há uma compreensão difusa de que a superlotação é consequência direta e exclusiva do aumento nas taxas de criminalidade, argumentaremos que se trata de um fenômeno multidimensional em que é necessário considerar também parâmetros legais e seus efeitos organizacionais. A dimensão normativa constitui o foco deste trabalho, ${ }^{2}$ e a análise comparativa de algumas diretrizes permite contrastar legislações e demais documentos oficiais relevantes que tratem da problemática da superlotação.

O contraste entre os casos brasileiro e francês possibilita compreender como países que têm por base diretrizes que se aproximam no modo de organizar sua justiça juvenil (Bugnon, 2020; Marinho; Vargas, 2015; Santos, 2018) lidam de modo diverso com a superlotação: se legislações brasileiras e francesas ressaltam a dimensão protetiva e educativa do sistema

1 Este artigo apresenta resultados parciais da pesquisa "Segurança socioeducativa e superlotação: um estudo exploratório sobre a construção organizacional de procedimentos e afetos", apoiada com recursos do edital 2019 "APQ1 - Auxílio à Pesquisa básica" da Faperj. Somado a isso, a análise comparada entre Brasil e França é resultado do estágio doutoral da primeira autora realizado na França entre 2016 e 2017, e da experiência de pesquisa da segunda autora no Brasil entre 2009 e 2012. O estágio da primeira autora foi desenvolvido com apoio do projeto internacional de cooperação e aperfeiçoamento "Passagens de Fronteiras e Cidades Seguras: Questões históricas e contemporâneas", realizado entre Núcleo de Estudos da Cidadania, Conflito e Violência Urbana da Universidade Federal do Rio de Janeiro (NECVU-UFRJ) e Centre des Recherches Sociologiques sur le Droit et les Institutions Pénales (Cesdip). A pesquisa da segunda autora foi realizada com o apoio dos seguintes projetos: "Conflits urbains, violence et processus de criminalisation" desenvolvido pela Universidade Federal do Rio de Janeiro, Universidade Federal de Minas Gerais e pela Universidade de Lille 1 (França) e apoiado pelo Programa CAPES-COFECUB, e 2) "SpaceControl" (Logiques et dynamiques du contrôle socio-spatial des jeunes des classes populaires), apoiado pelo projeto ANR que resulta também de uma cooperação entre pesquisadores na França e no Brasil.

${ }^{2}$ Ao focar a dimensão normativa da produção da superlotação, não queremos dizer que esta é resultado exclusivo de leis inadequadas. Ao contrário, como será mencionado posteriormente, a superlotação pode ser analisada igualmente com base no contexto político, no nível institucional e também segundo as práticas dos operadores do sistema socioeducativo (sobretudo no que se refere às decisões dos juízes). Entretanto, este texto faz uma análise exploratória cujo foco é o conteúdo de textos jurídicos e normativos e as estatísticas disponíveis como um modo de iniciar uma aproximação com esse tema. 
de justiça juvenil, a análise comparada permite constatar que esses países lidam de modo diferente com um problema considerado central para a plena realização de um modelo reabilitador de sanção.

A análise comparada aqui proposta não almeja simplesmente demonstrar que esses países se esforçam de modo diferenciado no combate à superlotação, mas complexificar esse debate de modo a ir além de sua constatação. Ao nos debruçarmos especificamente sobre regulações legais e normativas, será possível evidenciar a contribuição dessas para o aumento e diminuição da superlotação em instituições privativas de liberdade para adolescentes. Ao olhar o modo diverso como França e Brasil regulam a superlotação em seus sistemas socioeducativos, será possível perceber que, mesmo não sendo autônomas (Gonçalves, 2005), legislações, normativas e diretrizes podem efetivamente ter impacto tanto nas dinâmicas relacionadas à superlotação quanto nos modos como tal fenômeno é considerado pelos diversos atores do sistema de justiça juvenil.

Para a realização desse debate, este artigo está organizado em três seções, além desta introdução e das considerações finais: inicialmente apresentamos as características do sistema de sanções a adolescentes acusados de atos infracionais no Brasil e na França para, em seguida, discutir algumas diretrizes que nos aproximam do debate sobre superlotação. Nesse momento, contrastamos tais diretrizes com algumas análises sobre o próprio conceito de superlotação, de modo a complexificá-lo para além da constatação de que se trata da inadequação entre número de vagas e número de internos. Posteriormente, descrevemos como ocorre o debate sobre superlotação em unidades privativas de liberdade para adolescentes no contexto brasileiro e francês, evidenciando singularidades e disputas sobre modos de lidar com a superlotação nos dois países. Como conclusão, discutimos que a definição de superlotação é um resultado político da interação entre sistema de justiça, governos e ativistas, o que abre espaço para 
questionar a privação de liberdade como resposta inevitável e autoevidente a atos infracionais.

\section{Contrastando o contexto brasileiro com o francês}

Tanto no Brasil quanto na França a punição de menores de idade se orienta oficialmente pela preocupação em articular processos educativos durante a sanção do adolescente. Essa orientação compartilhada autoriza olhar para os dois contextos de modo comparativo, apesar das diferenças referentes à organização social, cultural e política entre os países.

Um primeiro ponto a destacar são as datas de publicação das leis atualmente responsáveis por tutelar essa parcela da população, o Estatuto da Criança e do Adolescente (ECA, Lei Federal no 8.069, de 13 de julho de 1990) ${ }^{3}$ e a Ordonnance du 2 février 1945, lei que regula as formas de proteção e punição a adolescentes na França. Enquanto no Brasil o ECA foi promulgado logo após a reabertura democrática (1990), na França isso se deu logo após o fim da Segunda Guerra Mundial (1945), revelando momentos de fortes mudanças sociais em ambos os casos. Nesse sentido, é importante destacar que a Ordonnance de 1945 foi reformada mais de 40 vezes desde sua promulgação, tornando-se, ao longo do tempo, cada vez mais repressiva (Bailleau, 2009), enquanto o ECA não recebeu mudanças substanciais no que se refere à justiça juvenil e às medidas socioeducativas, ainda que haja movimentos atuais que demandam a redução da maioridade penal e o aumento do tempo de internação (Santos; Vinuto, 2020).

Ambas as legislações abandonam a noção de discernimento em prol da compreensão de que menores de idade são "sujeitos em desenvolvimento" e, por isso, priorizam legalmente sanções educativas. Entretanto, nos dois países há uma certa desconexão entre o marco jurídico e as práticas do atores do sistema, como afirmam Frederico Marinho e Joana Vargas (2015, p. 272).

3 Para uma comparação histórica das legislações brasileiras e francesas e sobre as instituições socioeducativas nos dois países, ver Santos, 2018. 
No Brasil, apesar dos discursos oficiais, o caráter liberal e progressista da legislação apresenta grande dificuldade de se integrar às práticas das organizações e dos profissionais responsáveis pelos adolescentes infratores. $\mathrm{Na}$ França, ao contrário, desde a década de 1990, após as sucessivas alterações e retificações, afirma-se que a execução das políticas criminais tem sido mais liberal do que a legislação.

Na França observa-se uma inércia do modelo histórico baseado na proteção, apesar das reformas legislativas que criminalizam adolescentes, enquanto no Brasil, o marco legal baseado na proteção tem dificuldades em se implementar, devido à longa história de práticas autoritárias e violentas por parte do Estado dirigidas a populações pobres.

Há também diferenças notáveis entre os dois códigos, já que, ao contrário do Brasil, em que a execução da medida socioeducativa de internação fica a cargo das unidades federativas - o que gera grandes variações estaduais na política de atendimento em meio fechado - na França as sanções privativas de liberdade são administradas em âmbito nacional. Aqui é importante destacar a atuação da Protection Judiciaire de la Jeunesse (PJJ - Proteção Judiciária da Juventude), divisão administrativa autônoma, vinculada ao Ministério da Justiça, que tem como missão a proteção de crianças e adolescentes em situação de risco, vulnerabilidade ou delinquência. ${ }^{4}$ A PJJ atua na implementação de políticas, no gerenciamento de instituições de acolhimento e internação e na gestão de recursos humanos, com especial atenção ao treinamento de educadores ${ }^{5}$ que atuam tanto em meio aberto quanto no meio fechado (Sallée, 2016).

A PJJ atua tanto nos estabelecimentos penitenciários para adolescentes quanto em unidades fechadas ("centres fermés") definidas como medidas

${ }^{4}$ Vale lembrar que o termo "delinquente" é considerado pejorativo no Brasil, mas é de uso corrente na França.

${ }^{5}$ Para saber mais, ver http://www.enpjij.justice.fr/la-direction-de-la-protection-judiciaire-dela-jeunesse-dpjj. Acesso em 14/04/2021. 
educativas, ${ }^{6}$ além do acompanhamento dos adolescentes em meio aberto. No Brasil, não há qualquer instituição semelhante à PJJ e nem sempre há diálogo entre centros de internação (organizados pelo executivo estadual), medidas socioeducativas em meio aberto ${ }^{7}$ (executadas no nível municipal) e medidas protetivas (executadas a nível municipal). ${ }^{8}$

É digno de destaque que, a partir dos anos 1990, houve na França uma multiplicação de novos dispositivos "fechados" (Sallée, 2014) apresentados como "alternativas ao encarceramento" para jovens considerados "reincidentes" ou "com dificuldades múltiplas". Assim, a França conta atualmente com uma vasta gama de instituições restritivas e privativas de liberdade, a saber:

- Centre de Placement Immédiat: ${ }^{9}$ unidade de urgência para acolhimento de adolescentes acusados de atos infracionais, coordenada pela PJJ. O tamanho dessas unidades varia e os adolescentes podem ficar internados por no máximo três meses.

- Centre Éducatif Renforcé (CER): ${ }^{10}$ unidade privativa de liberdade para adolescentes reincidentes com "dificuldades múltiplas" (familiares, sociais, escolares, problemas de saúde física ou psicológica), coordenada pela PJJ. Nesse tipo de unidade, pode

\footnotetext{
${ }^{6}$ A PJJ não atua de modo idêntico em instituições de encarceramento e nos "centros fechados", já que há diferenças substanciais nas possibilidades de exercício de suas prerrogativas. Detalharemos essas diferentes instituições mais à frente.

${ }^{7}$ Notadamente a Liberdade Assistida e a Prestação de Serviços à Comunidade.

${ }^{8}$ Segundo o artigo 101 do ECA, a autoridade competente poderá determinar, dentre outras, as seguintes medidas protetivas: I - encaminhamento aos pais ou responsável, mediante termo de responsabilidade; II - orientação, apoio e acompanhamento temporários; III - matrícula e frequência obrigatórias em estabelecimento oficial de ensino fundamental; IV - inclusão em serviços e programas oficiais ou comunitários de proteção, apoio e promoção da família, da criança e do adolescente; $\mathrm{V}$ - requisição de tratamento médico, psicológico ou psiquiátrico, em regime hospitalar ou ambulatorial; VI - inclusão em programa oficial ou comunitário de auxílio, orientação e tratamento a alcoólatras e toxicômanos; VII - acolhimento institucional; VIII - inclusão em programa de acolhimento familiar; IX - colocação em família substituta.

${ }^{9}$ Centro de Colocação Imediata.

${ }^{10}$ Centro Educativo Reforçado.
} 
haver no máximo oito adolescentes internados, cuja sanção pode durar até seis meses, renovável uma vez.

- Centre Éducatif Fermé (CEF): ${ }^{11}$ unidade privativa de liberdade para adolescentes multireincidentes, coordenada pela PJJ. Nesse tipo de unidade pode haver no máximo doze adolescentes internados, cuja sanção pode durar até seis meses, renovável uma vez.

- Établissement Pénitenciaire pour les Mineurs (EPM): ${ }^{12}$ unidade penitenciária destinada exclusivamente a adolescentes, coordenada pelo Departamento Nacional de Administração Penitenciária. Nesse tipo de unidade, pode haver no máximo sessenta adolescentes internados, divididos em 10 unités de vie ${ }^{13}$ com no máximo 10 adolescentes cada. Nessas unidades não há um tempo máximo de internação, mas a duração média é de até 3 meses.

- Quartier Mineur: ${ }^{14}$ espaços para adolescentes dentro de penitenciárias para adultos, coordenadas pelo Departamento Nacional de Administração Penitenciária. Trata-se de unidades usualmente (mas nem sempre) direcionadas para adolescentes em situação de internação provisória e que são separadas dos espaços para adultos. Havia promessas de que essas unidades fossem substituídas pelos EPM, mas a existência destas permanecem. O tamanho dessas unidades varia, assim como a duração da internação.

As três primeiras instituições citadas referem-se a instituições restritivas de liberdade tidas como alternativas ao encarceramento, sendo consideradas medidas educativas ainda que sejam privativas de liberdade. Já o Établissement Pénitenciaire pour les Mineurs e o Quartier Mineur são, de fato, unidades

${ }^{11}$ Centro Educativo Fechado.

${ }^{12}$ Estabelecimento Penitenciário para Menores.

${ }^{13}$ Unidades de vida.

${ }^{14}$ Em tradução livre seria "Bairro de Menores", mas o termo se refere a espaços internos às prisões de adultos reservadas para receber exclusivamente adolescentes. 
prisionais, revelando que a França mantém instituições distantes do ideal reabilitador tão singulares à justiça juvenil (Bailleau; Milburn, 2014).

Outro ponto relevante é que, na França, há uma diferença notável entre "penas" e "medidas educativas" ou "sanções educativas", já que, como dito, lá um adolescente pode, de fato, ser encarcerado. Da mesma forma, embora haja sanções educativas privativas de liberdade, as instituições francesas que as executam são consideradas não coercitivas (Sallée, 2016). Assim, como atesta também Bugnon (2020), o fato de categorizar uma medida como "educativa" ou "de proteção" acaba limitando o debate sobre sua dimensão coercitiva. Isso pode ter como consequência uma restrição de liberdade muito mais longa nesses dispositivos ditos "educativos" do que nas instituições de encarceramento, onde as garantias jurídicas (brevidade, excepcionalidade e ultima ratio) limitam a duração da pena. Enquanto isso, no Brasil, não há encarceramento de adolescentes em termos legais, mas não é raro que os centros de internação sejam pejorativamente qualificados como verdadeiras prisões (Vinuto; Franco, 2019). Além disso, o mecanismo que define a duração da privação de liberdade é muito diferente no Brasil, já que o juiz não determina essa duração no momento do julgamento: é o comportamento do adolescente - retratado pelos técnicos em relatórios enviados ao juiz - que determina a continuação ou o fim da medida (Bugnon, 2020). ${ }^{15}$

É importante lembrar que, no caso brasileiro, o ECA altera substancialmente o modo como crianças e adolescentes são legalmente definidos, deixando de ser objetos de intervenção para serem "sujeitos de direitos", a partir do alinhamento com a Doutrina da Proteção Integral (Zamora, 2005). Um dos pontos mais afetados por essa lei foi o tratamento direcionado a crianças e adolescentes a quem se atribui a prática de atos infracionais, cuja sanção não deve priorizar a privação de liberdade. $\mathrm{O}$ ECA estabelece seis diferentes tipos de sanções, chamadas de medidas socioeducativas, a saber: advertência, obrigação de reparar o dano, prestação de serviços à comunidade, liberdade assistida, inserção em regime de

${ }^{15}$ A duração de uma medida socioeducativa não pode, entretanto, ultrapassar 3 anos. 
semiliberdade ou internação em estabelecimento educacional. Dentre essas, a internação é considerada a mais grave, por ser privativa de liberdade. Internação e semiliberdade são executadas pelos governos estaduais, enquanto as medidas socioeducativas em meio aberto são executadas em âmbito municipal. ${ }^{16}$ No caso da internação, como discutiremos posteriormente, não há um regimento que regule o número máximo de vagas para as entidades estaduais, ainda que existam esforços de alguns grupos para estabelecer um parâmetro nacional de limite máximo de lotação nos centros de internação.

Agora que algumas aproximações e distanciamentos entre os sistemas brasileiros e francês foram descritas, podemos realizar apropriadamente o debate específico sobre superlotação. Assim, passaremos a apresentar algumas discussões que tentam conceituar esse fenômeno.

\section{Disputas e sentidos sobre a superlotação}

Como sabemos, há várias normativas intergovernamentais que buscam criar parâmetros mínimos de atendimento a crianças e adolescentes a quem se atribui prática de ato infracional. Uma das primeiras dessas orientações foi a Declaração dos Direitos da Criança, enunciada em 1924, ainda no contexto da chamada Liga das Nações. Tal declaração foi seguida pela Declaração Universal dos Direitos da Criança, aprovada na Assembleia Geral das Nações Unidas em 1959, que, por sua vez, foi sucedida pela Convenção Internacional sobre os Direitos da Criança, ratificada pela ONU em 1989. De modo abrangente, tais normativas destacam a necessidade de garantir direitos, cuidados e assistência específicos a crianças e adolescentes, que necessitariam de proteção especial por sua condição de sujeito em

16 Para uma discussão mais detida sobre medida em meio aberto, ver Bugnon (2020), Bugnon e Duprez (2010) e Paula (2011).it delves into the paradox of an institution exerting control over youths while at the same time promoting their autonomy and responsibility. The study sheds light on the specific logics of power, control, and inequality produced by such institutional settings. The book's analysis is based on an ethnographic study of 'Assisted Freedom' (Liberdade Assistida 
desenvolvimento. Devido a tal especificidade, a Convenção de 1989 já declarava que a punição privativa de liberdade para menores de idade deveria ser mobilizada apenas como uma medida breve e excepcional, além de destacar que alternativas à privação de liberdade devem ser priorizadas. Tais orientações aparecem em diretrizes igualmente importantes, sobretudo nas Regras Mínimas das Nações Unidas para a Administração da Justiça Juvenil (Regras Mínimas de Beijing), adotada em 1985, que destaca em seu artigo 18.1 a necessidade de haver uma ampla variedade de medidas de modo a evitar a institucionalização de menores de idade.

Tais normativas internacionais oferecem diretrizes gerais para minimizar o uso da privação de liberdade de adolescentes, mas não apresentam orientações explícitas para proibir a superlotação. No entanto, a constante menção de que a privação de liberdade deve ser excepcional pode ser pensada como uma orientação latente sobre a necessidade de impedir a existência de unidades superlotadas. ${ }^{17}$

Para compreender adequadamente as disputas e os sentidos em torno da superlotação, vale a pena dialogar com autores que se debruçaram sobre o sistema prisional adulto, já que é nesse âmbito que esses debates se apresentam com mais força. Há um consenso entre alguns ativistas e pesquisadores de que a superlotação é prejudicial, a ponto de ser considerada uma forma de tortura (Souza, T. 2018), já que agrava as condições já degradantes de aprisionamento. ${ }^{18} \mathrm{O}$ Mecanismo Estadual de Prevenção e Combate à Tortura do Rio de Janeiro lista alguns pontos relevantes sobre o sistema penitenciário adulto que podem ser estendidos para qualquer instituição de privação de liberdade.

\footnotetext{
17 De qualquer forma não se deve negligenciar que as sanções em meio aberto, ainda que não afetem as taxas de lotação de unidades privativas de liberdade, também indicam expansão do poder punitivo do Estado (Bugnon, 2015, 2020).

${ }^{18} \mathrm{Em}$ sua dissertação sobre a atuação da rede de organizações e coletivos em prol do desencarceramento, Juliana Coelho Almeida (2020) apresenta disputas em torno da ampliação do conceito de tortura, com destaque para a mobilização de egressos do sistema prisional e seus familiares em prol de uma definição que considere a vida diária na prisão como uma forma de tortura por si só.
} 
A realidade perene de superlotação conduz a violação de inúmeros direitos reconhecidos aos presos. Nas unidades superlotadas é comum o cenário de precariedade material, grande acúmulo de lixo, péssimas condições de aeração, fornecimento inadequado de roupas de cama, colchões e insumos de higiene pessoal, presos dormindo no chão, aviltante revezamento para concessão do banho de sol, tempo reduzido para visitas e escassez de vagas para atividades laborativas e educacionais quando existentes. Tal panorama encontra-se em total desconformidade com parâmetros internacionais (Rio de Janeiro, 2012, p. 37).

Como vemos, a superlotação acarreta, necessariamente, violações de direitos das pessoas encarceradas. Entretanto, alguns autores argumentam que a solução para esse estado de coisas não passa pelo aumento do número de vagas em unidades privativas de liberdade Ariza Higuera e Torres Gómez (2019) criticam a ausência de critérios internacionalmente aceitos para mensurar a superlotação em diferentes contextos, ressaltando que o modo usual de a quantificar é insuficiente, pois se baseia apenas na existência de espaço em um alojamento, desconsiderando outros aspectos da vida prisional que vão além da ocupação de uma cela. Para os autores, o cálculo das taxas de superlotação também deveria levar em conta a disponibilidade de um espaço externo comum, um espaço sanitário adequado com chuveiro e vaso sanitário, um espaço adequado para comer e espaços para atividades de ressocialização. Os autores propõem um cálculo de superlotação que leve em conta a densidade nas unidades privativas de liberdade, que seria considerada a partir da relação entre quantidade de pessoas encarceradas e o espaço que estas podem efetivamente usufruir.

Pensar em termos de densidade prisional, além de complexificar o debate sobre superlotação ao considerar a qualidade do contexto no qual a sanção será cumprida, tem a vantagem de minimizar tentativas de camuflagem do número de vagas disponíveis nas unidades, o que pode ocorrer ao colocar mais beliches ou colchões em um alojamento sem que isso melhore as condições de trabalho e de vida na unidade. Entretanto, grande parte do debate público sobre superlotação se restringe à demanda por construção de mais unidades. Isso ocorre porque, na maioria das vezes, 
se define a superlotação como resultado direto e exclusivo do aumento da criminalidade e, portanto, torna-se razoável pensar que é necessário construir novas unidades para lidar com o problema. Assim, o debate sobre densidade prisional requer um debate anterior sobre as próprias causas da superlotação.

Muitas pesquisas têm mostrado que governos, polícias e sistemas de justiça não reagem de modo imparcial à criminalidade, o que explica o aumento do encarceramento mesmo quando as taxas de criminalidade diminuem ou se mantêm estáveis (Alexander, 2017; Lemgruber; Fernandes, 2015; Wacquant, 2007). Ao contrário, tais instituições atuam de modo ativo no aumento das taxas de encarceramento, sendo centrais para a compreensão do processo consensualmente chamado de "encarceramento em massa". Para Garland (2001), trata-se de um fenômeno recente, sem paralelo na história, caracterizado por colossais números absolutos de pessoas presas e pela concentração territorial dos efeitos da prisão já que regras internas a esta passam a ser elemento relevante para a dinâmica de bairros empobrecidos e racializados que costumam ser alvo preferencial da repressão estatal. Desse modo, o encarceramento em massa se revela como uma política que não foi proposta, debatida ou democraticamente acordada, mas que define muitas sociedades atualmente. Segundo Garland (2001, p. 1-2), ${ }^{19}$

o aprisionamento se torna aprisionamento em massa quando deixa de ser o encarceramento de criminosos individuais e se torna a prisão sistemática de grupos inteiros da população. No caso dos EUA, o grupo em questão é, evidentemente, o dos jovens negros do sexo masculino nos grandes centros urbanos. Para estes segmentos da população, a prisão tornou-se normalizada. Tornou-se uma parte regular e previsível da experiência, e não um acontecimento raro e infrequente. (Tradução nossa).

\footnotetext{
19 "Imprisonment becomes mass imprisonment when it ceases to be the incarceration of individual offenders and becomes the systematic imprisonment of whole groups of the population. In the case of the USA, the group concerned is, of course, young black males in large urban centres. For these sections of the population, imprisonment has become normalized. It has come to be a regular, predictable part of experience, rather than a rare and infrequent event".
} 
Garland concorda em que o encarceramento em massa não é resultado inequívoco do aumento das taxas de criminalidade, mas produto da convergência entre políticas públicas e cálculos políticos em que governantes angariam vantagens ao vincular-se aos discursos de lei e ordem, sobretudo no que se refere à guerra às drogas. Por isso, um dos pontos que ajuda a compreender o encarceramento em massa é o chamado "populismo penal", definido por Pratt (2007) como um processo em que governos desenvolvem políticas de segurança de acordo com o que acreditam ser as aspirações do público em geral, revelando que o interesse é aumentar sua própria popularidade e não controlar o crime. Pratt $(2007$, p. 3) afirma: "[e]m suma, o populismo penal consiste na busca de um conjunto de políticas penais para ganhar votos em vez de reduzir a criminalidade ou promover a justiça".$^{20}$ Podemos dizer que, no Brasil, um desses inimigos comuns é o que popularmente se nomeia como "menor infrator", imagem fortemente marcada pela sujeição criminal (Misse, 2010).

Assim, a superlotação também é efeito do populismo penal, e olhar para esse panorama ajuda a entender o debate colocado por Devresse (2013). A autora argumenta que grupos em espaços de poder, ao definir a superlotação como resultado exclusivo do aumento na criminalidade, justificam a impossibilidade de garantir os direitos das pessoas presas sem jamais questionar as políticas de segurança ou as atuações profissionais que as sustentam. A autora defende que a luta contra a superlotação passa pela regulamentação da admissão de entradas em instituições privativas de liberdade conjugada com a facilitação de liberações antecipadas ou ajustes de sentenças. Entretanto, Devresse destaca a existência de poucas iniciativas do poder público para incentivar e regulamentar tais práticas.

Somado a isso, a superlotação também decorre das práticas cotidianas dos operadores do sistema de justiça, sobretudo os juízes que, tanto na França quanto no Brasil, têm bastante autonomia na aplicação a lei

20 "In short, penal populism consists of the pursuit of a set of penal policies to win votes rather than to reduce crime or to promote justice". 
e podem acentuar ou reduzir discursos punitivos realizados nos níveis governamentais ou institucionais. De acordo com Delarre (2012), as reformas francesas que acarretaram endurecimento da justiça juvenil tiveram um efeito limitado nas decisões dos juízes, que continuam atuando a partir de um discurso protetivo próprio da Ordonnance de 1945. Já o caso brasileiro parece ser menos promissor. Priscila Coelho (2020) demonstra como o poder judiciário brasileiro, ao operar através da lógica da segurança pública, orienta-se mais por valores como "autonomia funcional dos juízes" ou "necessidade de proteção da sociedade" do que pela busca por garantia de direitos. Por isso, juízes não costumam perceber como sua a atribuição de minimizar o problema da superlotação, demonstrando grande resistência à adoção de medidas desencarceradoras e limitandose a defender a construção de novas unidades para abertura de mais vagas. No que se refere ao socioeducativo, de acordo com Flora Souza (2018), apesar de o ECA se opor ao uso da privação de liberdade como resposta primordial aos atos infracionais, há um aumento exponencial de adolescentes internados. Mas, ao mesmo tempo, no Rio de Janeiro ${ }^{21}$, esses adolescentes costumam ser privados de liberdade por menos tempo do que os adultos, o que decorre tanto do marco jurídico que estabelece três anos como período máximo de internação de adolescentes, como também de um efeito não antecipado da superlotação crônica existente no sistema socioeducativo fluminense (Souza, F., 2018). Desse modo, sanções curtas seriam fundamentais para a instituição executora da medida socioeducativa lidar com os efeitos da superlotação produzidos no âmbito do judiciário.

Resumindo, propomos discutir a superlotação como um fenômeno complexo, produzido pela interação entre grupos e instituições diversas, como sistema de justiça, governos e políticos, além de ativistas, que, por sua vez, pressionam o Estado para que este cumpra com suas prerrogativas

${ }^{21}$ A pesquisa de Flora Souza se refere ao estado do Rio de Janeiro, mas, segundo o Conselho Nacional do Ministério Público (CNMP, 2019), tal panorama também se apresenta em outros estados. 
de garantia de direitos. É sobre tais interações que discutiremos a seguir, considerando que a questão da superlotação permite abordar e revelar paradoxos quanto ao tema mais geral da garantia de direitos das populações presas. ${ }^{22}$ Como sublinha Caldeira (1991) o conceito de "direitos humanos" aplicado às populações presas sofre de uma legitimidade muito frágil no Brasil, tanto que em certos discursos públicos os direitos humanos são sinónimos de "privilégios de bandidos".

Passemos, agora, à análise comparativa sobre o fenômeno da superlotação no Brasil e na França. Para tanto, apresentamos informações relevantes sobre a trajetória social que tornou a superlotação um problema social nos dois países, bem como os modos diferenciados como se tem reagido a tal fenômeno em cada contexto. Além disso, apresentamos alguns dados quantitativos referentes ao número de adolescentes privados de liberdade nos dois países. É necessário ter precaução ao olhar para tais números, já que não é possível realizar uma comparação estatística direta entre estes, como se retratassem a realidade tal como ela é. Ao contrário, estatísticas são sempre seletivas, socialmente construídas e afetadas por subnotificações, indicando apenas o que é registrado pelas instituições. No que se refere à superlotação, isso fica especialmente claro quando olhamos para unidades brasileiras que não estão superlotadas, mas têm "fila de espera", isto é, adolescentes aguardando a liberação de vagas para serem internados quando possível (CNMP, 2019). Tais filas de espera também revelam desproporção entre a oferta e a demanda de vagas e, ainda que não produzam superlotação, acarretam inúmeros outros problemas, como o envio de adolescentes para unidades distantes de seu local de residência ou a ansiedade sentida pelo adolescente ao não saber quando encerrará sua sanção.

22 Nesse sentido, é importante destacar que, ainda que a superlotação seja um problema social central no que se refere à garantia de pessoas que se encontram em privação de liberdade, ela não é o único fator explicativo da deterioração do ambiente de internação no Brasil. A marginalização das atividades educativas e a existência de episódios de violência ocorrem muito antes da superlotação ganhar as proporções atuais (Salles Filho, 2003). 


\section{Superlotação na medida socioeducativa de internação em diretrizes brasileiras}

Há um desafio particular para acessar informações sobre a quantidade de adolescentes que cumprem medidas socioeducativas no Brasil. Apesar de haver previsão legal, os dados sobre os sistemas socioeducativos estaduais e municipais são escassos, não padronizados e também não são claros sobre as metodologias utilizadas nos irregulares levantamentos nacionais (Almeida; Vinuto, 2020). Também não há integração entre as diferentes instituições envolvidas no julgamento do ato infracional e na execução das medidas socioeducativas, o que acarreta dados díspares que nem sempre dialogam entre si, prejudicando as possibilidades de análise histórica e tornando os dados pouco confiáveis. Considerando tais limitações, os dados oficiais apresentados no Levantamento Anual do Sinase ${ }^{23}$ referente ao ano de 2017 (Brasil, 2019) indicam que havia 24.803 adolescentes e jovens entre 12 e 21 anos cumprindo medidas socioeducativas em meio fechado. Dentre estes, 17.811 adolescentes cumpriam medida de internação (71,8\%), 2.160 estavam sob regime de semiliberdade (8,7\%) e 4.832 em internação provisória (19,5\%). Havia também 117.207 adolescentes cumprindo medidas socioeducativas em meio aberto, sendo que 69.930 cumpriam prestação de serviços à comunidade e 84.755 estavam sob liberdade assistida. Desse modo, em 2017, havia, no Brasil, 142.010 adolescentes cumprindo alguma medida socioeducativa ${ }^{24}$.No mesmo Levantamento Anual consta que, em 2017, havia 484 unidades de medidas em meio fechado em todo o Brasil, o que totalizava 22.846 vagas. Dessas vagas, 15.061 eram em unidades de internação, revelando a existência de um déficit geral de 1.957 vagas para essa medida privativa de liberdade. O Rio de Janeiro era o segundo estado com maior déficit de vagas, já que

${ }^{23}$ Sistema Nacional de Atendimento Socioeducativo, Lei Federal no 12.594 , de 18 de janeiro de 2012.

${ }^{24}$ Para uma discussão sobre relatórios de medidas socioeducativas e a falta de transparência que pauta esse debate, ver Almeida e Vinuto (2020). 
havia 1.148 adolescentes internados, mas apenas 656 vagas em centros de internação. Infelizmente, os dados disponíveis nesse relatório não possibilitam a elaboração de uma série histórica, mas outros trabalhos indicam que os níveis de superlotação nas unidades cariocas variam de acordo com dinâmicas sociais mais amplas. Um exemplo bastante ilustrativo é apresentado no relatório "Megaeventos, repressão e privação de liberdade no Rio de Janeiro" produzido pelo Mecanismo Estadual de Prevenção e Combate à Tortura, em que se apresenta o crescimento desproporcional do número de adolescentes privados de liberdade às vésperas da Copa do Mundo FIFA de Futebol Masculino, que foi realizada entre o dia 12 de junho e 13 de julho de 2014. Segundo o relatório,

esta constatação nos impõe a leitura de que se instalou no estado do Rio de Janeiro, quiçá no Brasil, um verdadeiro estado de exceção, em que adolescentes eram apreendidos pelas forças de segurança e mantidos privados de sua liberdade pelo Poder Judiciário com vistas à higienização da cidade sede da partida final da Copa do Mundo de Futebol (Rio de Janeiro, 2014, p. 75, grifos nossos).

Como um efeito dramático desse contexto de superlotação, potencializado na era dos megaeventos no Brasil, podemos citar o incêndio ocorrido em uma unidade masculina no Rio de Janeiro no dia de abertura dos Jogos Olímpicos de Verão de 2016. Os adolescentes de um alojamento tentaram fazer um remendo na televisão para assistir à cerimônia de abertura da Olimpíada, mas a fiação de uma extensão pegou fogo, causando um incêndio que acarretou a morte de dois adolescentes, além de outros feridos. ${ }^{25}$ Nesse momento, a Defensoria Pública do estado do Rio de Janeiro declarou que o ECA prevê que, quando não há vagas na medida de internação, os adolescentes têm o direito de cumprir alguma medida em meio aberto, ${ }^{26}$

25 Para mais informações, ver Daflon, 2016.

${ }^{26}$ Sobre a situação das medidas socioeducativas em meio aberto, ver https://www.mds. gov.br/webarquivos/publicacao/assistencia_social/relatorios/Medidas_Socioeducativas_em Meio Aberto.pdf. Acesso em 05 set. 2021. 
desde que não respondam por ato infracional com uso de violência ou grave ameaça contra a pessoa. No entanto, conforme a própria Defensoria, esse tipo de transferência raramente ocorre. É importante destacar que a ocorrência de óbitos no sistema socioeducativo não é raridade, pois no já referido Levantamento Anual do Sinase consta que em 2017 houve 46 mortes de adolescentes em unidades socioeducativas brasileiras, sendo vinte e oito delas durante o cumprimento da medida de internação, dez durante a semiliberdade e quatro durante a internação provisória, restando quatro casos sem informações sobre a medida socioeducativa que cumpriam os adolescentes no momento de sua morte (Brasil, 2019).

A superlotação acarreta outros efeitos mais corriqueiros na rotina de um centro de internação, como o descumprimento do artigo 123 do ECA, que determina a separação de adolescentes por critérios de idade, compleição física e gravidade da infração. Mas, apesar dos inúmeros efeitos da superlotação na execução da medida socioeducativa de internação, até bem pouco tempo não havia uma normativa geral que interditasse claramente a existência de unidades superlotadas. A elaboração da própria lei do Sinase exemplifica a dificuldade em institucionalizar diretrizes sobre o tema: em 2006, o Sinase foi lançado como resolução do Conselho Nacional dos Direitos da Criança e do Adolescente (CONANDA - Resolução 119, de 11 de dezembro de 2006) ${ }^{27}$ e, em 2012, foi aprovado como lei (Lei Federal n. 12.594, de 18 de janeiro de 2012). A resolução estabelece que a lotação dos centros de internação não deveria ultrapassar 40 adolescentes por unidade, sendo que esta deveria ser constituída por módulos com capacidade para no máximo quinze adolescentes e, no caso de haver mais de uma unidade em um mesmo terreno, a lotação total não poderia ultrapassar 90 adolescentes. Entretanto, quando se tornou lei, o Sinase não incorporou a imposição desses parâmetros gerais sobre lotação máxima.

${ }^{27}$ Para acessar as resoluções elaboradas pelo Conanda entre 1993 e 2004, ver https://www. gov.br/mdh/pt-br/acesso-a-informacao/participacao-social/conselho-nacional-dos-direitosda-crianca-e-do-adolescente-conanda/resolucoes/resolucoes-1-a-99.pdf. Acesso em 05 set. 2021. 
Em 2015 o Supremo Tribunal Federal (STF) foi interpelado a se posicionar sobre o sistema penitenciário adulto, a partir do julgamento da Arguição de Descumprimento de Preceito Fundamental no 347, momento em que declarou que a situação prisional no país enfrentava um "estado de coisas inconstitucional" por violar sistematicamente os direitos fundamentais das pessoas presas. ${ }^{28} \mathrm{Em}$ um movimento semelhante, alguns grupos ativistas demandaram que o STF também se posicionasse sobre a regulação da superlotação nas unidades socioeducativas. Em 2018, iniciou-se o julgamento do habeas corpus coletivo $143.988^{29}$ ajuizado pela Defensoria Pública do Espírito Santo sobre lotação na Unidade de Internação Regional Norte. Nesse julgamento, o relator do caso, ministro Edson Fachin, determinou que a taxa de ocupação na unidade não deveria ultrapassar 119\% de lotação. Sobre o efeito do reconhecimento de estados de coisas inconstitucional das prisões brasileiras por parte do STF, bem como do julgamento do referido habeas corpus coletivo, Mariana Chies Santos afirma que

o reconhecimento do HC Coletivo impetrado pela Defensoria Pública do Estado do Espírito Santo, que ingressamos como amicus curea, e a concessão da liminar pelo Ministro Fachin representa[m] uma grande vitória para quem luta há anos para assegurar não só o Princípio da Prioridade Absoluta para os Adolescentes privados de suas liberdades e que t[ê]m seus direitos violados, mas para reconhecer a ilegalidade e o estado de coisas inconstitucional também dos Centros de Internação no Brasil, que apresentam estrutura precária e condições de superlotação degradantes para o fim [a] que se destinam (STF..., 20/08/2008). ${ }^{30}$

Em 2019 as Defensorias dos estados da Bahia, Ceará, Pernambuco e Rio de Janeiro também pleitearam a decisão do referido habeas corpus, que foi concedida. A partir de então, as unidades superlotadas desses estados

\footnotetext{
${ }^{28}$ Para um debate sobre as decisões conservadoras dos ministros do STF sobre o estado de coisas inconstitucional das prisões brasileiras, ver Flauzina e Pires (2020).

${ }^{29}$ Para acessar o referido habeas corpus coletivo, ver http://redir.stf.jus.br/paginadorpub/paginador.jsp?docTP=TP\&doclD=753732203. Acesso em 14 abr. 2021.

30 Ver http://www.justificando.com/2018/08/20/stf-concede-liminar-em-favor-deadolescentes-sob-maus-tratos-no-es/. Acesso em 14 abr. 2021.
} 
deveriam transferir os adolescentes excedentes para outras unidades e os juízes da execução de medidas socioeducativas poderiam transferi-los para programas de meio aberto, o que já era estabelecido no próprio ECA. Mas, como não se tratava de uma legislação geral, na prática, tal decisão possibilitou que diferentes estados se pautassem por parâmetros diversos, já que a superlotação não estava regulada nas demais unidades federativas.

No ano seguinte, em 2020, a Segunda Turma do STF seguiu o voto do Ministro Fachin em decisão colegiada sobre o habeas corpus coletivo referente ao Espírito Santo, ${ }^{31}$ mas estabelecendo que, a partir de então, qualquer centro de internação do país não poderia mais ultrapassar a capacidade projetada (STF, 2020). Essa decisão tem força de lei e apenas o próprio STF pode alterá-la. Entretanto, o STF não fixou prazo para que a superlotação seja encerrada nas unidades do país, e ainda não há dados disponíveis para conhecer os efeitos de tal decisão sobre as taxas de lotação das unidades. Além disso, é importante lembrar que antes da decisão final do STF o mundo já tinha sido afetado pela pandemia de Covid-19, o que também teve efeitos nos níveis de superlotação dos cárceres do país. Pesquisas indicam que a Recomendação no 62 de 17 de março de 2020 emitida pelo Conselho Nacional de Justiça (CNJ), que estabeleceu medidas preventivas à propagação de infecção por Covid-19 nos sistemas penitenciário e socioeducativo, teve efeitos relevantes no declínio da lotação nas unidades socioeducativas do Rio de Janeiro (Vinuto et al., no prelo).

\section{Superlotação nas instituições para menores delinquentes em diretrizes francesas}

Como já mencionado, a legislação que regula o sistema de justiça juvenil francês é a Ordonnance du 2 février 1945 que, apesar de se manter por mais de 70 anos, recebeu algumas modificações ao longo do tempo. Dessas modificações resultou uma volta da dimensão repressiva e da

31 Para mais detalhes do referido voto, ver https://www.conjur.com.br/dl/nao-haversuperlotacao-unidades.pdf. 
"sanção" ou da "coerção" como respostas legítimas à delinquência juvenil, o que se observa nas expressões hoje centrais na França de contenance éducative (contenção educativa), sanction éducative (sanção educativa) ou éducation sous contrainte (educação sob coerção). Nicolas Sallée (2016) discorre sobre esse modelo educativo fundado em possibilidades diversas de coerção, o que tem modificado o panorama da justiça juvenil e a identidade profissional dos seus operadores. Para o autor, o modelo de éducation sous contrainte se caracteriza por uma valorização da coerção, em particular daquela ligada ao encarceramento, como o coração da ação educativa para adolescentes delinquentes. Tal modelo fica especialmente claro nas soluções de placement (colocação/ internação) que, mesmo sendo educativas, detêm características carcerárias, já que, nesses contextos privativos de liberdade, o objetivo final colocado aos profissionais é o de manter a ordem e evitar fugas. Assim, a lógica punitiva ocupa um lugar crescente no campo da justiça juvenil, e ainda que não substitua completamente a lógica educativa que prevalecia até então, transforma o sentido e o conteúdo das sanções direcionadas a adolescentes.

Para Sallée (2016), o símbolo dessa tensão é a votação da Lei de 9 de setembro de 2002, a "Lei de orientação e programação para a justiça", que recoloca a noção de responsabilidade no cerne do sistema de justiça juvenil. Também conhecida como Lei Perben I, tal lei estabeleceu novas sanções educativas a partir dos treze anos de idade e, nesse bojo, criou o CEF (Centre Éducatif Fermé) e o EPM (Établissement Pénitenciaire pour les Mineurs). Sallée demonstra que, desde então, há uma diminuição do encarceramento de adolescentes, mas um aumento no número de adolescentes internados em instituições educativas em meio fechado. Os números de internações nessas instituições não são contabilizados nas estatísticas de encarceramento, mas revelam uma quantidade cada vez maior de adolescentes inseridos em instituições coercitivas, em particular nos CEFs. Por isso, para Sallée, essas transformações falam 
menos sobre as taxas de encarceramento e mais sobre o significado que é dado a esse fenômeno.

Ao olhar para os números de adolescentes internados em instituições "alternativas ao encarceramento" e em estabelecimentos propriamente penitenciários, há aspectos que merecem destaque. Com relação ao número de adolescentes encarcerados, podemos olhar para o levantamento mensal disponibilizado pelo Ministério da Justiça, chamado "Estatísticas sobre a população detida e encarcerada". ${ }^{32}$ Em março de 2021 havia 789 adolescentes internados em EPMs ou QM (Quartier Mineur), instituições que conjuntamente totalizavam 1.149 vagas em 53 unidades. Desse modo, os dois tipos de instituição apresentam conjuntamente uma taxa de ocupação de $68,7 \%$, muito abaixo da lotação total disponível ${ }^{33}$. Somadas a esses dados, o Ministério da Justiça também publica anualmente informações sobre o funcionamento do Poder Judiciário no site "Références Statistiques Justice" ${ }^{34}$ Sobre o ano de 2019, o relatório indica que 63.300 adolescentes foram processados por tribunais franceses. Vemos, desse modo, um número relativamente baixo de adolescentes encarcerados, se comparado ao número total de adolescentes processados pelos tribunais.

Já o número de adolescentes internados em instituições educativas privativas de liberdade não é publicizado da mesma forma, mas os dados nos foram disponibilizados após uma solicitação ao serviço estatístico da PJJ. Tendo como parâmetro a data de 31 de dezembro de 2020, havia 470 adolescentes internados em CEFs para um total de 601 vagas, o que revela uma ocupação de $78,2 \%$, que também fica abaixo da capacidade institucional. No mesmo sentido, havia 131 adolescentes internados em CERs (Centre Éducatif Renforcé) para um total de 338 vagas, o que atesta a

\footnotetext{
32 Para acessar os dados de 2021, ver http://www.justice.gouv.fr/prison-et-reinsertion-10036/ les-chiffres-clefs-10041/statistiques-de-la-population-detenue-et-ecrouee-33736.html.

${ }^{33}$ Vale ressaltar que esses dados nacionais não permitem excluir uma superlotação ao nível local, como veremos posteriormente no caso do EPM em Marselha.

34 Ver http://www.justice.gouv.fr/statistiques-10054/references-statistiques-justice-12837/ justice-des-mineurs-donnees-2019-33705.html. Acesso em 01 ago. 2021.
} 
ocupação de $38,75 \%$ da capacidade das unidades. A explicação para uma taxa tão baixa de ocupação dos CERs se relaciona com as férias escolares, momento em que nem todas as unidades fazem atendimentos e, nesses casos, o adolescente pode ficar integralmente com sua família.

Pode-se compreender as baixas taxas de ocupação nas referidas instituições francesas como resultado das normativas relativas a sanções a adolescentes. No âmbito do Conselho da Europa, principal organização de defesa de direitos humanos do continente europeu, ${ }^{35}$ entra em vigor, em 1987, a Convenção Europeia para a Prevenção da Tortura e de Tratamentos ou Penas Cruéis, Desumanos ou Degradantes, ${ }^{36}$ que declara que as más condições materiais de detenção, muitas delas decorrentes da superlotação, podem equivaler a um tratamento desumano ou degradante. Posteriormente, em sua Recomendação CM/Rec(2008)11, ${ }^{37}$ que versa especificamente sobre as regras europeias para adolescentes sujeitos a sanções decorrentes de ato infracional, consta que os alojamentos das unidades devem respeitar a dignidade e a privacidade dos mesmos. Ainda nesse sentido, a Recomendação afirma, em seu artigo 63.2, que

os adolescentes devem, em princípio, ser alojados durante a noite em quartos individuais, exceto quando lhes pareça preferível partilhar quartos comuns. Os alojamentos só devem ser compartilhados se estiverem adequados para uso coletivo e devem ser ocupados por jovens reconhecidos como aptos a conviver juntos. Os adolescentes devem ser consultados antes de serem coagidos a compartilhar o alojamento durante a noite e devem poder indicar com quem desejam coabitar (grifos nossos). ${ }^{38}$

\footnotetext{
${ }^{35} \mathrm{O}$ Conselho da Europa compreende 47 Estados-Membros, incluindo os 27 países da União Europeia.

${ }^{36}$ Para acessar a Convenção, ver https://rm.coe.int/16806dbaa6.

${ }^{37}$ Ver https://www.refworld.org/pdfid/4a7058c02.pdf.

${ }^{38}$ Les mineurs doivent en principe être logés pendant la nuit dans des chambres individuelles, sauf lorsqu'il apparaît préférable pour eux qu'ils partagent des pièces communes. Les logements ne doivent être partagés que s'ils sont adaptés à un usage collectif et doivent être occupés par des mineurs reconnus aptes à cohabiter ensemble. Les mineurs doivent être consultés avant d'être contraints de partager des locaux pendant la nuit et doivent pouvoir indiquer avec quelle personne ils souhaitent cohabiter.

ver https://search.coe.int/cm/Pages/result details.aspx?ObjectlD=09000016805d2710.
} 
O debate relacionado aos quartos individuais para adolescentes internados é seriamente encarado no contexto francês, o que fica evidente em alguns atos públicos organizados por profissionais das unidades que desejam denunciar os momentos em que as taxas de ocupação não são respeitadas. A título de ilustração, citamos um trecho de uma reportagem sobre uma dessas manifestações.

Esta é a segunda vez este ano que os funcionários do l'établissement pénitentiaire pour mineurs (EPM) de Valentine, em Marselha, se manifestam. Em junho passado, eles já haviam denunciado a superlotação carcerária que conduz a tensões entre os jovens encarcerados e os guardas (...).

Eles querem que a capacidade de 55 lugares do EPM seja respeitada. A prisão para adolescentes marselhesa abriu suas portas em 2007 para acolher adolescentes problemáticos com idades entre 13 e 18 anos. Por vezes, há até 67 jovens na unidade. Os guardas denunciam uma situação desumana na qual os adolescentes internados são obrigados a dormir no chão sobre um colchão nos corredores devido à falta de espaço. ${ }^{39}$

Em sua experiência de estágio doutoral na França, a primeira autora teve a oportunidade de conhecer os trabalhos realizados em um CEF e em um EPM. Nesse momento, tanto profissionais quanto adolescentes ficaram espantados quando lhes foi informado que os adolescentes brasileiros não contavam com quartos individuais durante o cumprimento de sua medida socioeducativa. Foi comum ouvir que alojamentos com beliche impedem que os adolescentes "reflitam sobre seus erros" e se responsabilizem por seus atos infracionais, já que quartos compartilhados impediriam a

\footnotetext{
${ }^{39} \mathrm{C}^{\prime}$ est la deuxième fois cette année que le personnel de l'établissement pénitentiaire pour mineurs (EPM) de la Valentine à Marseille manifeste. En juin dernier, il avait déjà dénoncé la surpopulation carcérale qui engendre des tensions entre les jeunes incarcérés et envers les surveillants. Ils souhaitent que les capacités de 55 places de l'EPM soient respectées. La prison pour mineurs marseillaise a ouvert ses portes en 2007 pour prendre en charge des adolescents à problème de 13 à 18 ans. Ils sont parfois jusqu'à 67 jeunes. Les surveillants dénoncent une situation inhumaine où les jeunes détenus sont obligés de coucher parterre sur un matelas dans les couloirs, faute de place. Ver https://france3-regions.francetvinfo. fr/provence-alpes-cote-d-azur/bouches-du-rhone/metropole-aix-marseille/marseille/ etablissement-penitentiaire-mineurs-marseille-bloque-personnel-351645.html.
} 
privacidade, considerada fundamental para a ponderação e discernimento. Infelizmente, no Brasil, o problema vai além dos quartos compartilhados, já que são recorrentes as denúncias sobre adolescentes dormindo no chão em alojamentos superlotados. ${ }^{40}$

Não narramos tais situações com o objetivo de descrever o contexto francês como perfeito ou exemplar. Ao contrário, já mencionamos as tensões próprias do modelo de educação sob coerção, que ocorrem mesmo em um país do Norte global. Ainda assim, é interessante contrastar tais situações com o contexto brasileiro, que é o terceiro país que mais encarcera adultos no mundo. Isso ajuda a compreender, ao menos em parte, como a superlotação de adolescentes parece ser vista como fenômeno normal e inescapável. Ainda que no Brasil existam muitos grupos ativistas que impõem demandas ao sistema de justiça juvenil para fazer valer os direitos dos adolescentes internados, não há uma atuação organizada dos servidores das instituições executoras das medidas socioeducativas. Quando esses atuam, isso ocorre de modo individual junto a outros movimentos sociais mais gerais, como é o caso dos movimentos negro e abolicionista penal. Uma exceção notável é o Núcleo de Estudos Afro-Brasileiros do Departamento Geral de Ações Socioeducativas (NEAB-Degase), ${ }^{41}$ grupo de profissionais que discute questões relacionadas ao racismo de modo a não reproduzir hierarquias raciais em sua jornada de trabalho.

\section{Considerações finais}

Ao olhar leis e demais normativas, tanto nacionais quanto interestatais, que almejam regular a sanção direcionada a adolescentes acusados de cometer atos infracionais, fica claro o interesse em evitar a privação de liberdade, que não é vista como resposta incontornável às diversas dinâmicas criminais. Ainda assim, a superlotação marca vários sistemas penais e socioeducativos

${ }^{40}$ Um exemplo pode ser visto em: https://g1 .globo.com/ri/rio-de-janeiro/noticia/2018/10/11/ degase-unidades-do-rj-tem-superlotacao-divisao-por-faccoes-e-interna-com-recemnascido.ghtml.

${ }^{41}$ Para mais informações: https://www.facebook.com/neabnd2016/. 
pelo mundo. Não à toa, a superlotação tem ocupado lugar de destaque nos debates sobre privação de liberdade, fomentando uma discussão sobre como mensurá-la a fim de monitorar as condições de reclusão de pessoas encarceradas. Para contribuir com esse debate, propomos um diálogo com Ariza Higuera e Torres Gómez (2019) e suas discussões sobre densidade prisional para iluminar as descrições que fizemos sobre o contexto brasileiro e francês no que se refere a privação de liberdade de adolescentes.

Para lidar especificamente com a sanção direcionada a adolescentes acusados de cometer atos infracionais, tanto no Brasil quanto na França houve um esforço institucional em regular a superlotação, o que ocorreu de modos singulares em cada contexto. Enquanto no Brasil foi a sociedade civil que reivindicou, através da judicialização, um posicionamento do STF sobre o tema, a França se orientou por uma normativa europeia que impunha regras gerais aos diferentes Estados. Desse modo fica evidente que, como diz Marie-Sophie Devresse (2013), a superlotação se situa na encruzilhada entre distintos poderes de decisão de atores políticos diversos, sendo resultado da articulação de várias lógicas de intervenção.

Em ambos os países, ainda que leis não sejam suficientes para reorientar completamente as dinâmicas do sistema de justiça juvenil, são um passo inicial importante no processo de mudança institucional. Nessa perspectiva, a lei se torna elemento essencial da codificação e recodificação de demandas sociais, e sua mobilização se impõe como um modo relevante de regular a vida em instituições privativas de liberdade. A análise sobre tal cenário nos ajuda a compreender as disputas de sentido e de atribuições sobre o que é a superlotação, o que permite complexificar a ideia mobilizada por algumas figuras públicas de que esta é simplesmente uma inadequação entre número de vagas e número de internos que pode ser solucionada com a construção de novas instituições privativas de liberdade. Como dito anteriormente, esse tipo de narrativa só é considerada razoável porque sua base é a crença de que a superlotação é resultado exclusivo do aumento na criminalidade, o que foi destrinchado por vários autores apresentados até aqui. 
Ao trazer elementos para a análise das trajetórias de produção dessas normativas, torna-se possível questionar a privação de liberdade como resposta inevitável e autoevidente a atos infracionais. Tais trajetórias, construídas de modos específicos na França e no Brasil, revelam modos singulares de apoiar ou se opor às políticas de segurança nos dois países. Nesse sentido, discutir as disputas em torno da superlotação em unidades privativas de liberdade permite uma reflexão mais geral sobre o lugar dos "direitos humanos" (e, em especial, os direitos da criança) em ambos os contextos. Na França o modelo de proteção e educação na sanção de adolescentes levou décadas para se consolidar, e ainda que este esteja sendo questionado atualmente, as práticas dos operadores continuam seguindo orientações de caráter mais protetivo. Já no Brasil, vemos que houve rápidos avanços na elaboração do ECA após o período ditatorial, mas ainda há uma forte inércia nas representações e práticas sobre adolescentes que cometem atos infracionais. ${ }^{42}$ Desse modo, olhar atentamente para a superlotação ilumina esses diferentes lugares ocupados pelos direitos humanos de adolescentes encarcerados nos dois países, revelando paradoxos quanto ao tema mais geral da garantia de direitos das populações presas. Assim, se a superlotação não é a causa da deterioração de instituições privativas de liberdade para adolescentes, ainda assim, revela-se um indicador do pouco caso com que são tratados os direitos humanos de pessoas encarceradas no Brasil.

Juliana Vinuto é Doutora em Sociologia e pesquisadora de pós-doutorado pelo Programa de Pós-Graduação em Antropologia da Universidade Federal Fluminense.

$\bowtie$ j.vinuto@gmail.com

Géraldine Bugnon é Doutora em Sociologia e professora na Haute École de Travail Social. $\triangle$ geraldine.bugnon@hesge.ch

${ }^{42}$ A decisão do STF sobre lotação dos centros de internação podería ser um indice de mudança no Brasil, mas será necessário tempo para avaliar os efeitos dessa decisão, dado que é um esforço recente para regulamentar a questão. 


\section{Referências}

1. ALEXANDER, Michele. A nova segregação: racismo e encarceramento em massa. São Paulo: Boitempo, 2017.

2. GISI, Bruna; VINUTO, Juliana. Transparência e garantia de direitos no sistema socioeducativo: a produção de dados sobre medidas socioeducativas. Boletim IBCCrim, v. 28, n. 337, p. 4-7, 2020.

3. ALMEIDA, Juliana C. "Quem conhece cadeia não comemora a prisão de ninguém": uma etnografia sobre o MEPCT/RJ e a rede pelo desencarceramento no estado do Rio de Janeiro. 2020. Dissertação (Mestrado em Antropologia) Programa de Pós Graduação em Antropologia, Universidade Federal Fluminense, Niterói, 2020.

4. ARIZA HIGUERA, Libardo J.; TORRES GOMEZ, Mario A. Definiendo el hacinamiento. Estándares normativos y perspectivas judiciales sobre el espacio penitenciario. Estudios Socio-Jurídicos, v. 21, n. 2, 2 jul. 2019.

5. BAILLEAU, Francis. La France, une position de rupture? Deviance et Societe, v. 33, n. 3, p. 441-468, 2009.

6. BAILLEAU, Francis; MILBURN, Philip. Éduquer les mineurs en milieu carcéral en France. Deviance et Societe, v. 38, n. 2, p. 133-156, 2014.

7. BRASIL. Levantamento Anual Sinase 2017. Brasília: Ministério da Mulher, da Família e dos Direitos Humanos, 2019.

8. BUGNON, Géraldine. Governing delinquency through freedom: control, rehabilitation and desistance. Nova York: Routledge, 2020.

9. BUGNON, Géraldine. Governar por meio da liberdade: Controle difuso e normalização das subjetividades na medida de liberdade assistida no Brasil. Dilemas - Revista de Estudos de Conflito e Controle Social, n. Edição Especial 1, p. 205-234, 2015.

10. BUGNON, Gérandine; DUPREZ, Dominique. Olhares cruzados sobre o atendimento institucional aos adolescentes infratores no Brasil. Dilemas - Revista de Estudos de Conflito e Controle Social, v. 3, n. 7, p. 37, 2010.

11. CALDEIRA, Teresa. Direitos humanos ou "privilégios de bandidos". Novos Estudos Cebrap, v. 30, n. 1991, p. 162-74, 1991.

12. CNMP - Conselho Nacional do Ministério Público. Panorama da execução dos programas socioeducativos de internação e semiliberdade nos estados brasileiros. Brasília: CNMP, 2019.

13. COELHO, Priscila. Um preso por vaga: estratégias políticas e judiciais de contenção da superlotação carcerária. 2020. Dissertação (Mestrado em Direito e Desenvolvimento) - Escola de Direito de São Paulo, Fundação Getúlio Vargas, São Paulo, 2020.

14. DAFLON, Rogério. O Estado devolveu meu filho morto. Agência Pública, 7 dez. 2016. Disponível em: https://apublica.org/2016/12/o-estado-devolveumeu-filho-morto/. 
15. D’ANGELO, Luisa. B.; HERNÁNDEZ, Jimena de G. Sexualidade, um direito (secundário)? Atravessamentos entre sexualidade, socioeducação e punição. Plural, v. 24, n. 1, p. 78-104, 2017.

16. DELARRE, Sébastien. Des discours aux chiffres : les effets d'une décennie de lois réformatrices en matière de justice des mineurs. Champ pénal/Penal field, v. IX, 2012.

17. DEVRESSE, Marie-Sophie. La gestion de la surpopulation pénitentiaire: perspectives politiques, administratives et juridictionnelles. Droit et societe, v. 84, n. 2, p. 339-358, 2013.

18. RIO DE JANEIRO. Relatório anual do Mecanismo Estadual de Prevenção e Combate à Tortura do Rio de Janeiro. Rio de Janeiro: Mecanismo Estadual de Prevenção e Combate à Tortura do Rio de Janeiro, 2012.

19. RIO DE JANEIRO. Relatório temático "Megaeventos, repressão e privação de liberdade no Rio de Janeiro". Rio de Janeiro: Mecanismo Estadual de Prevenção e Combate à Tortura do Rio de Janeiro, 2014.

20. BEATO FILHO, Claudio; SILVEIR, Andrea M.; RIBEIRO, Ludmila M. L.; ROCHA, Rafael L. S.; SOUZA, Rafaelle L.; OLIVEIRA, Victor N. Percepções sociais sobre o sistema prisional brasileiro: um estudo quantitativo. Revista Brasileira de Execução Penal - RBEP, v. 1, n. 1, p. 279-305, 2020.

21. FLAUZINA, Ana; PIRES, Thula. Supremo Tribunal Federal e a naturalização da barbárie. Revista Direito e Práxis, v. 11, n. 2, p. 1211-1237, 2020.

22. GARLAND, David (ED.). Mass imprisonment: social causes and consequences. Londres: Sage, 2001.

23. GONÇALVES, Hebe S. Medidas socioeducativas: avanços e retrocessos no trato do adolescente autor de ato infracional. In: ZAMORA, M. H. (Ed.). Para além das grades: elementos para a transformação do sistema socioeducativo. Rio de Janeiro; São Paulo: Editora PUC Rio; CIESPI ; Edições Loyola, 2005. p. 35-62.

24. LEMGRUBER, Julita; FERNANDES, Márcia. Tráfico de drogas na cidade do Rio de Janeiro: prisão provisória e direito de defesa. Boletim Segurança e Cidadania, n. 17. Rio de Janeiro: CESEC, 2015.

25. MARINHO, Frederico C.; VARGAS, Joana D. Permanências e resistências: legislação, gestão e tratamento da delinquência juvenil no Brasil e na França. Dilemas - Revista de Estudos de Conflito e Controle Social, número especial, p. 267-298, 2015.

26. MISSE, Michel. Crime, sujeito e sujeição criminal: aspectos de uma contribuição analítica sobre a categoria "bandido". Lua Nova: Revista de Cultura e Política, n. 79, p. 15-38, 2010.

27. PAULA, Liana de. Liberdade assistida: punição e cidadania na cidade de São Paulo. 2011. Tese (Doutorado em Sociologia) - Programa de Pós-Graduação em Sociologia, Universidade de São Paulo, São Paulo, 2011.

28. PRATT, John. Penal populism. Londres: Routledge, 2007. 
29. SALLÉE, Nicolas. Les mineurs délinquants sous éducation contrainte. Deviance et Societe, v. 38, n. 1, p. 77-101, 31 mar. 2014.

30. SALLÉE, Nicolas. Éduquer sous contrainte : une sociologie de la justice des mineurs. Paris: EHESS, 2016.

31. SALLES FILHO, Belmiro F. Agente educacional, uma prática de amor e ódio no atendimento ao adolescente em conflito com a Lei. 2003. Tese (Doutorado em Saúde Pública) - Escola Nacional de Saúde Pública, Fundação Oswaldo Cruz, Rio de Janeiro, 2003.

32. SANTOS, Mariana C. Resistentes, conformados e oscilantes: um estudo acerca das resistências produzidas pelos adolescentes privados de liberdade no Brasil e na França. 2018. Tese (Doutorado em Sociologia) - Programa de Pós-Graduação em Sociologia, Universidade Federal do Rio Grande do Sul, Porto Alegre, 2018.

33. SANTOS, Mariana C.; VINUTO, Juliana. Punir adolescentes na França e no Brasil: legislações, instituições e equilíbrio entre sanção e educação. Revista Brasileira de Ciências Criminais, v. 173, n. 28, p. 487-516, nov. 2020.

34. SOUZA, Flora. Entre leis, práticas e discursos: um estudo sobre o julgar em execução de medida socioeducativa de internação no Rio de Janeiro. 2018. Dissertação (Mestrado em Direito) - Programa de Pós-Graduação em Direito, Universidade do Estado do Rio de Janeiro, Rio de Janeiro, 2018.

35. SOUZA, Taiguara. A era do grande encarceramento: tortura e superlotação prisional no Rio de Janeiro. Rio de Janeiro: Revan, 2018.

36. STF - Supremo Tribunal Federal. Unidades de internação de adolescentes não podem ultrapassar capacidade projetada. Portal STF, 24 ago. 2020. Disponível em: http://portal.stf.jus.br/noticias/verNoticiaDetalhe. asp?idConteudo $=450193 \&$ ori $=1$.

37. VINUTO, Juliana. "O outro lado da moeda": o trabalho de agentes socioeducativos no estado do Rio de Janeiro. Rio de Janeiro: Autografia, 2020.

38. VINUTO, Juliana; FRANCO, Tulio M. "Porque isso aqui, queira ou não, é uma cadeia": as instituições híbridas de interface com a prisão. Revista Mediações, v. 24, n. 2, p. 265-277, 2019.

39. WACQUANT, Loic. Punir os pobres: a nova gestão da miséria nos Estados Unidos. Rio de Janeiro: Instituto Carioca de Criminologia : Revan, 2007.

40. ZAMORA, Maria Helena. Para além das grades: elementos para a transformação do sistema socioeducativo. Rio de Janeiro; São Paulo: Editora PUC Rio; CIEŞPI; Edições Loyola, 2005.

Recebido: 10 set. 2021. Aceito: 15 nov. 2021. 